\title{
A multi-syringe flow injection system for the spectrophotometric determination of trace levels of iron in waters using a liquid waveguide capillary cell and different chelating resins and reaction chemistries
}

\author{
Ricardo N.M.J. Páscoa, Ildikó V. Tóth, António O.S.S. Rangel * \\ CBQF/Escola Superior de Biotecnologia, Universidade Católica Portuguesa, Rua Dr. António Bernardino de Almeida, 4200-072 Porto, Portugal
}

\begin{abstract}
A B S T R A C T
A method integrating a long waveguide capillary cell with a preconcentration resin in a multi-syringe flow injection analysis (MSFIA) system for iron determination in waters was developed. The determination of iron is based on a colorimetric reaction and two reagents were tested, ferrozine and ammonium thiocyanate. A liquid waveguide capillary cell $(1.0 \mathrm{~m}$ pathlength, $550 \mu \mathrm{m}$ i.d. and $250 \mu \mathrm{L}$ internal volume) with a preconcentration resin were used to improve the sensitivity of the determination. Two different preconcentration resins were also tested, Chelex 100 and NTA Superflow. The developed method employing the NTA Superflow with ferrozine colorimetric reagent provided a detection limit of $0.05 \mu \mathrm{g} \mathrm{L}^{-1}$ with a linear response up to $8 \mu \mathrm{L} \mathrm{L}^{-1}$ and a sample throughput rate of 12 per hour. The developed system presents low reagents/sample consumptions. The accuracy was assessed using a certified reference water sample.
\end{abstract}

\section{Keywords:}

Iron

Multi-syringe flow injection analysis

Liquid waveguide capillary cell

Pre-concentration resins

Spectrophotometry

\section{Introduction}

Iron is one of the most frequently determined analyte in environmental (like water, soil and sediment) samples [1]. This fact can be naturally attributed to the significant role of this analyte in the environmental geochemical cycles. In the last decades, the knowledge of the concentration of iron in natural waters is gaining importance. Despite being one of the most abundant elements on earth crust, it occurs at very low levels in ocean waters (3-112 $\mathrm{ng} \mathrm{L}^{-1}$ ) being a limiting nutrient for phytoplankton growth $[2,3]$. As it is recognized now, variation of iron concentration can ultimately affect the oceans carbon cycle and has consequent implications in climate change [4].

The main form of iron in waters is iron (III), however only a small fraction occurs in a free hydrated form. Iron (II) is highly soluble but rapidly oxidized to iron (III) [5]. It is present at very low concentrations levels in waters and its determination is particularly difficult because of the complexity of the matrix and also because of the different physical, chemical and biological processes involved [6]. Furthermore, iron is omnipresent in many materials and equipment, increasing the risk of contamination [5]. In order to overcome these difficulties and to increase sensitivity, separation and/or preconcentration is an important and frequently applied tool [7].

There is a wide variety of possible instrumental methods, spectrophotometry [8-10], chemiluminescence [11], HPLC [12], adsorptive stripping voltammetry [13], fluorescence [14], inductively coupled mass spectrometry (ICP-MS) [15] and atomic absorption spectrometry (AAS) [16] for detection of iron. However when trace levels of the analyte is concerned, the applicable detection methods are reduced.

Flow analysis systems provide several advantages for sample manipulation including simplicity, equipment cost, accuracy, good reproducibility, elevated sample throughput, in-line sample manipulation, high degree of automation and reduction in the consumption of samples/reagents and in effluent production $[8,17,18]$.

There are several spectrophotometric systems for iron determination using different flow strategies. Some of these applications use this determination as a case study to demonstrate the capabilities of some newly developed flow handling techniques. In this context, Pons et al. summarizes the development and improvement of flow procedures based on using the same reaction chemistry for the determination of iron in different flow strategies [19]. Within the published spectrophotometric flow methods there are several that use preconcentration/separation approaches incorporated in FIA [20], SIA [21], MSFIA [10] and multi-pumping [9] manifolds.

MSFIA is one of the most recent flow analysis techniques and it was first proposed by Cerdà and co-workers [22]. Among with other flow analysis techniques, it offers high sampling rate, robustness, versatility and low consumption of reagents and samples [23]. MSFIA combines the multi-channel operation of flow injection analysis with the ability to select the exact volumes of sample and reagents needed for analysis, as it is carried out in sequential injection analysis (programmable flow) mode. One not frequently mentioned, but not less important characteristics of the MSFIA system is that it is also able to work under 
moderate backpressure, thus is very suitable when using intercalated resins $[18,19]$ or even monolithic columns [24].

Various resins are described in literature as C18 [20], Amberlite XAD4 [25], MAF-8HQ [26], 8HQ [27], Chelex 100 [19,21] and NTA Superflow $[7,28]$ for iron preconcentration. The latter NTA Superflow resin was originally designed for high throughput sample clean-up procedures based on the affinity chromatography concept. It presents several advantages as, the analyte recovery at low $\mathrm{pH}$ and the supported high flow rates which is very interesting for using in applications where high sampling rate is needed. Recently, this commercial resin was applied for the preconcentration of total iron in low $\mathrm{pH}$ open sea water samples [7]. The developed work presented remarkable analytical characteristics; those in one part can be attributed to the new resin and in other part to the applied ICP-MS detector.

One objective of this work was to apply and compare the characteristics of the NTA resin to the well established Chelex 100 cationic exchange resin (operating at a higher $\approx 4 \mathrm{pH}$ range), under flow analysis conditions and using a spectrophotometric detection system with a liquid waveguide capillary cell. In the LWCC, the spectrophotometric pathlength is increased without considerable light attenuation [29]. The light is carried by means of an optical fiber to the LWCC where it undergoes total internal reflection on the cell walls. The potential to exploit this equipment was only possible since 1993 with Teflon AF-2400 (DuPont Fluroproducts, DE, USA). This polymer is chemically stable, inert and is mainly transparent through UV and visible range with refractive index (1.29) lower than water (1.33) [30].

The ultimate objective of the work was to develop an automated method capable to detect and quantify low levels of iron in waters, with minimized reagent consumption. For this purpose the LWCC and a preconcentration mini-column were coupled to a MSFIA system. Two different chemistries were applied for downstream spectrophotometric detection of iron in the different oxidation states of $\mathrm{Fe}^{2+}$ and $\mathrm{Fe}^{3+}$, involving the colorimetric reagents ferrozine and ammonium thiocyanate, respectively.

\section{Experimental}

\section{Reagents and solutions}

Ultra pure water from a MilliQ system (resistivity $>18 \mathrm{M} \Omega \mathrm{cm}^{-1}$ ) was used for the preparation of all solutions and all chemicals were analytical-reagent grade. Iron (III) stock standard solutions (10 $\mathrm{mg} \mathrm{L}^{-1}$ ) were prepared by diluting commercial $1000 \mathrm{mg} \mathrm{L}^{-1}$ iron atomic absorption standards (VWR-Spectrosol) in $0.01 \mathrm{~mol} \mathrm{~L}^{-1} \mathrm{HCl}$ solution. Within the linear response range, several working standard solutions from 1 to $8 \mu \mathrm{g} \mathrm{L}^{-1}$ in $0.01 \mathrm{~mol} \mathrm{~L}^{-1} \mathrm{HCl}$ solution were prepared daily from the stock solution. Iron (II) stock standard solution ( $\left.100 \mathrm{mg} \mathrm{L}^{-1}\right)$ was prepared by dissolving ammonium iron (II) sulphate hexahydrate (Merck) in $0.01 \mathrm{~mol} \mathrm{~L}^{-1} \mathrm{HCl}$ solution. River water certified reference material (NCR-SLRS-4) was also analysed for the evaluation of the accuracy of the developed method as recommended by the National Council of Canada.

Ferrozine solution of $2.5 \mathrm{mmol} \mathrm{L}^{-1}$ was prepared daily by dissolving $0.0185 \mathrm{~g}$ of ferrozine reagent $\left(\mathrm{C}_{20} \mathrm{H}_{14} \mathrm{~N}_{4} \mathrm{O}_{6} \mathrm{~S}_{2}\right)$ in a $2 \%(\mathrm{w} / \mathrm{v})$ ascorbic acid solution prepared in a $2 \mathrm{~mol} \mathrm{~L}^{-1}$ acetic acid ammonium acetate solution where the final $\mathrm{pH}$ was adjusted with acetic acid to 4.5.

The ammonium thiocyanate solution of $1.5 \mathrm{~mol} \mathrm{~L}^{-1}$ was prepared by dissolving $11.4 \mathrm{~g}$ of the solid $\left(\mathrm{CH}_{4} \mathrm{~N}_{2} \mathrm{~S}\right)$ in a $100 \mathrm{~mL}$ of MilliQ water.

The Chelex 100 resin (Bio-Rad, 200-400 mesh, sodium form) was suspended in a conditioning buffer obtained from $6.56 \mathrm{~g}$ of sodium acetate and $16 \mathrm{~mL}$ of concentrated acetic acid solution in $200 \mathrm{~mL}$ of water and with final $\mathrm{pH}$ adjusted with acetic acid to 4 . The same procedure was adopted to prepare the conditioning buffer/complexing agent solution, with water being replaced by a $1 \mathrm{~mol} \mathrm{~L}^{-1}$ sodium chloride solution. The $1 \mathrm{~mol} \mathrm{~L}^{-1}$ sodium chloride solution was prepared by dissolving $5.84 \mathrm{~g}$ of sodium chloride in $100 \mathrm{~mL}$ of water.
The resin NTA Superflow resin (Qiagen Inc., Valencia, CA) is available in a form of suspension therefore it is ready to use.

The resins were packed in PVC tubing $(2.22 \mathrm{~mm}$ i.d. and $2.5 \mathrm{~cm}$ length) and the suspensions introduced into the column by means of Pasteur pipette. Ordinary dishwashing foam was placed at both ends of the column to entrap the resins inside. Before application to iron determination the prepared resin columns were washed with $1.0 \mathrm{~mol}$ $\mathrm{L}^{-1} \mathrm{HCl}$ solution, until stable $(\mathrm{RSD}<3 \%)$ blank reading was obtained.

\section{Apparatus}

Solutions were propelled through a multi-syringe burette (Crison Instruments, Allela, Spain). The device uses a multiple-channel piston pump, containing up to four syringes, driven by a single motor, controlled by computer software through a serial port. Three-way commutation valves (NResearch, Caldwell, NJ, USA) were connected at the head of each syringe.

Two syringes of $10 \mathrm{~mL}$ were placed in position 1 and 2 and two syringes of $2.5 \mathrm{~mL}$ were placed in positions 3 and 4 . Hamilton (ref. 81620 and 81420) glass syringes were used. The piston movement of the multi-syringe was divided in 16,000 steps, therefore the minimum volume delivered was 0.62 for the $10 \mathrm{~mL}$ syringes and $0.16 \mu \mathrm{L}$ for the $2.5 \mathrm{~mL}$ syringes. For all solenoid valves, the exchange options were classified in on/off lines. The "on" line was assigned to the flow network and the "off" line to the solution flasks (represented with a solid line and dotted line, respectively on Fig. 1). The commutation valves used in this work had an internal volume of $27 \mu \mathrm{L}$ (ref. 161T031). All tubes connecting the different components of the set up were made of PTFE (Omnifit, Cambridge, UK) with $0.8 \mathrm{~mm}$ id and end fittings and connectors were also used (Gilson, Villiers-le-Bel, France). The sample loop (SL) and the reaction coil (r) were 800 and $100 \mathrm{~cm}$ long, respectively.

A personal computer Pentium II, running SCIWARE (Palmanyola, Mallorca, Spain) Auto-analysis software (version 5.0.3.5) controlled the multi-syringe operation (direction of piston displacement, number of steps and position of all commutation valves).

The spectrophotometric measurements were carried out at the wavelength of 480 and $562 \mathrm{~nm}$ for the detection of iron-ammonium thiocyanate and iron-ferrozine complex, respectively. Reference wavelength for minimizing the schlieren effect was set at $700 \mathrm{~nm}$. As detection system, an Ocean Optics PC2000-ISA (Winter Park, USA) spectrophotometer, a pair of $200 \mu \mathrm{m}$ fiber optic cable, a DH-2000

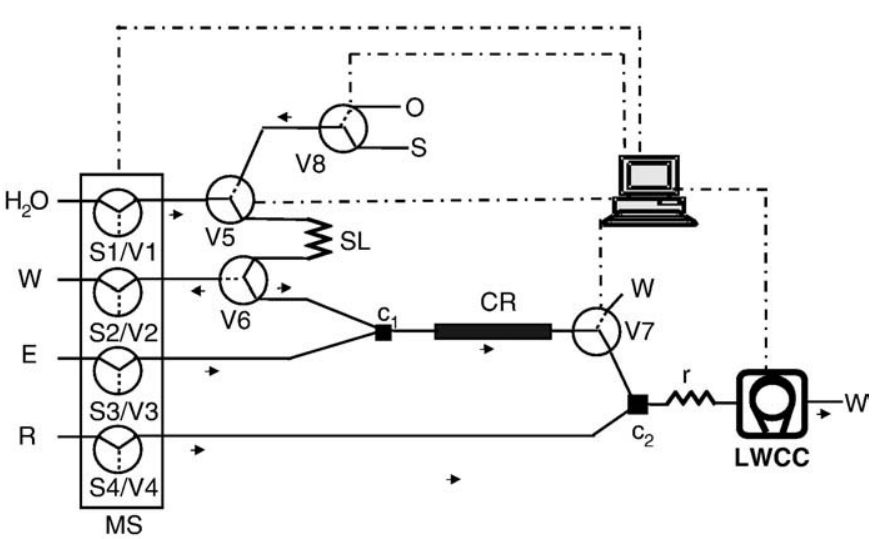

Fig. 1. Multi-syringe flow injection analysis manifold for the determination of iron in waters. $\mathrm{S}_{\mathrm{i}}$ : syringes; $\mathrm{V}_{\mathrm{i}}$ : solenoid valves in position "on" (discontinuous line) or "off" (continuous line); SL: sample loop $(4 \mathrm{~mL}) ; \mathrm{r}$ : reaction coil $(100 \mathrm{~cm}) ; c_{\mathrm{i}}$ : confluence; LWCC: detector (100 cm optical path, 480 and $562 \mathrm{~nm}$ for ammonium thiocyanate and ferrozine, respectively); MS: multi-syringe module; CR: chelating resin (NTA Superflow or Chelex 100); W: waste; S: sample or standard, O: oxidant (and conditioning agent for Chelex 100 resin); E: eluent; R: color reagent (ammonium thiocyanate or ferrozine). 
Table 1

MSFIA protocol sequence for the determination of iron in waters.

\begin{tabular}{|c|c|c|c|c|c|c|c|c|c|c|c|c|}
\hline \multirow[t]{2}{*}{ Step } & \multirow{2}{*}{$\begin{array}{l}\text { Piston } \\
\text { movement }\end{array}$} & \multicolumn{8}{|c|}{ Position of solenoid valves } & \multirow{2}{*}{$\begin{array}{l}\text { Volume } \\
(\mathrm{mL})\end{array}$} & \multirow{2}{*}{$\begin{array}{l}\text { Flow rate } \\
\left(\mathrm{mL} \min ^{-1}\right)\end{array}$} & \multirow[t]{2}{*}{ Description } \\
\hline & & $\overline{\mathrm{V} 1}$ & V2 & V3 & V4 & V5 & V6 & V7 & $\overline{V 8}$ & & & \\
\hline 1 & Dispense & 0 & 0 & 0 & 1 & 0 & 0 & 1 & 0 & 1.3 & 4 & Cleaning the chelating resin \\
\hline 2 & Pick up & 0 & 1 & 0 & 0 & 1 & 1 & 0 & $0 / 1$ & $3.6^{\mathrm{s}} ; 0.9^{\mathrm{o}}$ & 5 & Aspirate sample and oxidant \\
\hline 3 & Dispense & 1 & 0 & 0 & 0 & 0 & 0 & 1 & 0 & 4.5 & 2.5 & Propel sample through the resin \\
\hline 4 & Dispense & 0 & 0 & 0 & 1 & 0 & 0 & 0 & 0 & $0.25^{\mathrm{e}}$ & 2 & Propel eluent through the resin \\
\hline 5 & Dispense & 0 & 0 & 1 & 1 & 0 & 0 & 0 & 0 & $0.25^{\mathrm{e}} ; 0.25^{\mathrm{r}}$ & 2 & $\begin{array}{l}\text { Propel eluent and colour reagent } \\
\text { to the detector }\end{array}$ \\
\hline 6 & Dispense & 1 & 0 & 0 & 0 & 0 & 0 & 0 & 0 & 2.5 & 3 & $\begin{array}{l}\text { Propel reaction mixture to the detector } \\
\text { and signal registration }\end{array}$ \\
\hline
\end{tabular}

s-sample; ${ }^{\circ}$-oxidant; ${ }^{\text {e-eluent; }}{ }^{\text {r-colour reagent; } 0-o f f ; ~ 1-o n . ~}$

deuterium halogen light source (Top Sensor Systems, Eerbeek, The Netherlands) and a liquid waveguide capillary cell (LWCC 2100, World Precision Instruments, Sarasota, USA) (1.0 m pathlength, $250 \mu \mathrm{L}$ inner volume, $550 \mu \mathrm{m}$ inner diameter) was used.

Data acquisition was performed by Auto-analysis computer software.

\section{MSFIA procedure and system and figuration}

The protocol sequence is listed in Table 1 . The first step consists in washing and conditioning the chelating resin. Afterwards, a total volume of 3.6 and $0.4 \mathrm{~mL}$ of sample and oxidant, respectively, are aspirated to the sample loop via syringe 2 in a binary sampling mode. The aspirated solution sequence was made up as 0.2/1.8/0.1/1.8/0.1 mL of alternating oxidant and sample plugs. Then, the mixture contained in the sample loop (SL) is propelled through the chelating resin and solenoid valve (V7) to waste. The elution of the retained analyte is carried out in two steps. First, $0.25 \mathrm{~mL}$ of the eluent is propelled through the resin. At the second phase, a portion of the colour reagent $(0.25 \mathrm{~mL})$ is introduced at confluence $2\left(c_{2}\right)$, downstream and simultaneously with the second part $(0.25 \mathrm{~mL})$ of the eluent. In the final step the resulting mixture is transported to the detector and the analytical signal is registered.

The MSFIA system was designed to permit the determination and monitoring of iron in estuarine waters at low concentrations. To attain this objective, the advantages of the increased sensitivity of LWCC and the preconcentration chelating resin were coupled in this MSFIA manifold. Four solenoid valves were included (Fig. 1) in the set-up. The sampling step was based on the aspiration of the sample into a fixed volume sample loop, as introducing the sample to the system from one of the syringes would require cumbersome washing steps to avoid contamination between consecutive solutions. For that reason, three additional solenoid valves (V5, V6 and V8) were attached to the system. The solenoid valve V7 was connected to minimize the contact between the solutions and the flow cell.

The volume of the sample introduced was controlled by the length of the sample loop and the binary sampling technique was used to promote a better mixing between the sample or standard with the oxidant (when using Chelex 100 resin the solution of oxidant was prepared with conditioning buffer/complexing agent solution for resin regeneration). The binary sampling mode was achieved by rapid commutation of valve V8, allowing the consecutive and alternate aspiration of plugs of sample and oxidant, promoting their mutual overlapping before filling the injection loop. If this mixing was achieved with a conventional confluence, the sample would be diluted and the repeatability would be compromised.

\section{Results and discussion}

Several physical and chemical parameters were studied and optimised by the univariate method, where only one parameter was changed while others were kept constant.

\section{Study of physical and chemical parameters}

Initial studies for setting up of the physical parameters of the system were carried out using the ammonium thiocyanate reagent with both resins. First, the effect of the size of the resin column was studied by changing the length $(10-50 \mathrm{~mm})$ and the diameter $(1.65-2.29 \mathrm{~mm})$ of the PVC tubing. The highest sensitivity was achieved using the dimensions of $25 \mathrm{~mm}$ of length and $2.29 \mathrm{~mm}$ of diameter, for longer columns the operational stability decreased. In preliminarily studies it was observed that Chelex 100 resin became more compressed than NTA Superflow resin at the same flow rates and this alteration was more evident in longer columns.

The influence of the sample volume was studied using injection volumes in the range of $1-5 \mathrm{~mL}$. Increasing the sample volume increased the sensitivity of the method without evidence on saturating the resin column (please find corresponding calibration curves in within the electronic supporting information), however considerable increase in cycle time was registered. A $4 \mathrm{~mL}$ sample volume was selected as a compromise between low detection limits and cycle time.

As the elution step was reported to be largely predominant upon the extraction step [31], the following study consisted in evaluating the effect of the eluent plug size on sensitivity. The range studied for the plug size of the eluent was $0.125-0.5 \mathrm{~mL}$ and the best sensitivity was obtained with $0.25 \mathrm{~mL}$ (for both steps 4 and 5, Table 1 ). The influence of plug size of the colour reagent on the sensitivity was also studied between 0.0625 and $0.5 \mathrm{~mL}$ and $0.25 \mathrm{~mL}$ was chosen because it presented the highest sensitivity.

Following this, the effect of the length of the reaction coil ( $r$ ) on the sensitivity of the method was studied for lengths between 25 and $200 \mathrm{~cm}$ and the $100 \mathrm{~cm}$ was selected as allowed better sensitivity, while in longer reactors the sensitivity decreased probably due to the increased sample dispersion.

At the end of the physical setup, the effect of the flow rate of every step in the analytical cycle was also evaluated and the results are summarised in Table 2 . The flow rate for each step was selected as a compromise between sensitivity, shorter cycle time and low pressure for the resins columns.

The chemical variables studied included the eluent concentration, the $\mathrm{pH}$ and the concentration of ascorbic acid.

Firstly, the effect of the $\mathrm{HCl}$ eluent concentration was studied in the range of $0.25-1.5 \mathrm{~mol} \mathrm{~L}^{-1}$ and $1.0 \mathrm{~mol} \mathrm{~L}^{-1}$ was chosen because it

Table 2

Study of the flow rates for the steps of the analytical cycle.

\begin{tabular}{lll}
\hline Step & Range studied $\left(\mathrm{mL} \mathrm{min}^{-1}\right)$ & Selected value $\left(\mathrm{mL} \mathrm{min}^{-1}\right)$ \\
\hline 1 & $1-5$ & 4 \\
2 & $1-10$ & 5 \\
3 & $1-5$ & 2.5 \\
4 & $1-5$ & 2 \\
5 & $1-5$ & 2 \\
6 & $1-5$ & 3 \\
\hline
\end{tabular}


presented the highest sensitivity and same as the $1.5 \mathrm{~mol} \mathrm{~L}^{-1}$ solution. The elution step is particularly studied in the literature and it is an important parameter. It is generally accepted that the most appropriate acids to elute is $\mathrm{HCl}[27,31]$ and $\mathrm{HNO}_{3}$ [21]. Lohan et al. reported no difference between the two acids when applied as elution solutions, and the manufacturer of the LWCC recommended the use of hydrochloric acid in order to prevent flow cell damage, therefore this acid was applied.

The effect of the ammonium thiocyanate colour reagent concentration was studied in the range of $0.5-3 \mathrm{~mol} \mathrm{~L}^{-1}$ and the best sensitivity was obtained for $1.5 \mathrm{~mol} \mathrm{~L}^{-1}$.

Similarly, the effect of the ferrozine colour reagent concentration was tested in the range of $0.62-5.0 \mathrm{mmol} \mathrm{L}^{-1}$ and the concentration of $2.5 \mathrm{mmol} \mathrm{L}^{-1}$ allowed the highest sensitivity. When using ferrozine colour reagent, the effect of $\mathrm{pH}$ was studied in order to achieve a good compromise between total reduction of iron (III) to iron (II) and complex formation between iron (II) and ferrozine. For complete iron (III) reduction, $\mathrm{pH}$ must be below 4.2 [32]. An off-line study was performed in order to maintain the $\mathrm{pH}$ at the reduction step around $\mathrm{pH}$ 4.0 (the eluent had a concentration of $1.0 \mathrm{~mol} \mathrm{~L}^{-1} \mathrm{HCl}$ ). Therefore, the range of the concentration and the $\mathrm{pH}$ of the ammonium acetate buffer studied were $0.01-2.5 \mathrm{~mol} \mathrm{~L}^{-1}$ and $4-5 \mathrm{pH}$ units, respectively. Only a solution with $2.0 \mathrm{~mol} \mathrm{~L}^{-1}$ and $4.5 \mathrm{pH}$ units was capable to achieve the objective above. The concentration of ascorbic acid solution was varied between 1 and $4 \%(\mathrm{w} / \mathrm{v})$ and the minimum concentration to assure complete iron reduction was $2 \%(\mathrm{w} / \mathrm{v})$.

Finally, the effect of $\mathrm{H}_{2} \mathrm{O}_{2}$ oxidant concentration was studied using the NTA Superflow resin. For this study solutions of iron (II) and iron (III) were prepared from ammonium iron (II) sulphate hexahydrate and for iron (III) solution potassium permanganate was added to the standard solution as an oxidizing agent. The $\mathrm{H}_{2} \mathrm{O}_{2}$ concentration was varied between 0.002 and $0.2 \mathrm{~mol} \mathrm{~L}^{-1}$ and the minimum concentration necessary to oxide iron (II) to iron (III) in the samples/standards was $0.2 \mathrm{~mol} \mathrm{~L}^{-1}$.

Schlieren effect in the detection cell was noticed although it could be minimised by using a reference wavelength for monitoring the refractive index changes during measurement.

At the end of a working day, the LWCC was washed consecutively with $\mathrm{HCl}\left(0.05 \mathrm{~mol} \mathrm{~L}^{-1}\right)$ and $\mathrm{NaOH}\left(0.05 \mathrm{~mol} \mathrm{~L}^{-1}\right)$ solutions in counter current.

\section{Comparision of the resins}

It should be emphasized that the incorporated resin columns not only act as preconcentration units but as well have the objective of matrix removal. Both resins have been applied to the determination of trace elements in natural waters and efficient matrix removal was reported for NTA by Lohan and for Chelex 100 by Jiménez et al. in the case of application to sea water samples. However $\mathrm{pH}$ dependent swelling is frequently reported for Chelex and ammonium acetate washing of this column is necessary to remove alkaline and alkalineearth metals in excess.

These two resins were compared in several features. The use of Chelex 100 resulted in a higher sensitivity for iron (III) by comparison of the slopes of the equations of the calibration curves (same system set-up and the same ammonium thiocyanate reagent for both resins). The equations of the calibration curves for Chelex 100 and NTA Superflow resins were, Abs $=0.0371[\mathrm{Fe}]+0.6234$ and $\mathrm{Abs}=0.0197$ $[\mathrm{Fe}]+0.2278$, respectively. Iron concentration expressed as $\mu \mathrm{g} \mathrm{L}^{-1}$, (corresponding calibration curves can be found in ESI). However, with Chelex 100 resin, the use of a regeneration solution was imperative and this solution contributed to higher blank signals. The standard deviation from the ten consecutive injections of the blank was always higher. Consequently, both detection and quantification limits obtained were higher too. Additionally, at higher flow rates the compression of the column occurred and leak of the solutions passing through the column was noticed due to the increased pressure inside the system. In all these operational characteristics considered the NTA Superflow resin showed superior stability.

\section{Comparison of the reaction chemistries}

In this study, the two colour reactions were compared. The ferrozine reagent forms a complex with iron (II), therefore the solution containing ferrozine must have ascorbic acid in order to reduce all of the iron (III) to iron (II). The ammonium thiocyanate reagent forms a complex with iron (III), hence there is no need of iron (III) reduction. The equations of the calibration curves using ferrozine and ammonium thiocyanate with Chelex 100 resin are, Abs $=0.087[\mathrm{Fe}]+0.7806$ and Abs $=0.0371[\mathrm{Fe}]+0.6234$, respectively (corresponding calibration curves can be found in ESI). From the comparison of the slopes, it can be concluded that ferrozine reagent presents a higher sensitivity. The blank signals are quiet high for ferrozine reagent even though the detection and quantification limits are lower. This can only be attributed to the higher sensitivity. Hence, ferrozine colour reagent presented better option.

\section{Figures of merit}

All the analytical characteristics achieved using the two resins and colour reagents are summarized in Table 3. Both detection (LOD) and quantification (LOQ) limits were calculated as the concentration corresponding to the blank signal three and ten times the standard deviation, respectively, of ten consecutive blank injections [33].

The detection and quantification limits were always lower when using ferrozine colour reagent because of the higher sensitivity for iron. Although Chelex 100 resin presents a higher sensitivity for iron (III), as it was said above, it is the combination of NTA Superflow with ferrozine reagent that presents the lower detection and quantification limits. The innovation in this strategy lay on using a resin column that acts as a preconcentration and interference elimination unit and combine it with a LWCC in a MSFIA manifold. Nonetheless, with the increase of the light pathlength, all absorbance signals are amplified including the blank and in this case it can be a limitation for LWCC use, as high blank signals normally predict high detection and quantification values.

\section{Application to water samples}

Concluded the comparative studies, the method using NTA Superflow resin and ferrozine colour reagent was applied to a certified reference sample. The sample SLRS-4 with certified value of $103 \pm$ $5 \mu \mathrm{g} \mathrm{L}^{-1}$ was analyzed and the result obtained was $102 \pm 3 \mu \mathrm{g} \mathrm{L}^{-1}$.

Table 3

Figures of merit of developed methods.

\begin{tabular}{|c|c|c|c|c|}
\hline \multirow{2}{*}{$\frac{\text { Resin }}{\text { Reagents }}$} & \multicolumn{2}{|l|}{ Chelex 100} & \multicolumn{2}{|c|}{ NTA Superflow } \\
\hline & Thiocyanate & Ferrozine & Thiocyanate & Ferrozine \\
\hline Detection limit $\left(\mu \mathrm{g} \mathrm{L}^{-1}\right)^{\mathrm{a}}$ & 0.56 & 0.20 & 0.52 & 0.05 \\
\hline Quantification limit $\left(\mu \mathrm{g} \mathrm{L}^{-1}\right)$ & 1.15 & 0.83 & 1.16 & 0.08 \\
\hline Working range $\left(\mu \mathrm{L} \mathrm{L}^{-1}\right)$ & $0-20$ & $0-15$ & $0-50$ & $0-8$ \\
\hline Determination rate $\mathrm{h}^{-1}$ & 12 & 12 & 12 & 12 \\
\hline \multicolumn{5}{|l|}{$\begin{array}{l}\text { Reagent consumption } \\
\text { (mmol/assay) }\end{array}$} \\
\hline $\mathrm{HCl}$ & 0.5 & 0.5 & 0.5 & 0.5 \\
\hline Ammonium thiocyanate & 0.38 & - & 0.38 & - \\
\hline Ferrozine & - & 0.00062 & - & 0.00062 \\
\hline Hydrogen peroxide & 0.18 & 0.18 & 0.18 & 0.18 \\
\hline Acetic acid & 1.26 & - & 1.26 & - \\
\hline Sodium acetate & 0.36 & - & 0.36 & - \\
\hline Ascorbic acid & - & 0.028 & - & 0.028 \\
\hline Ammonium acetate/acetic acid & - & 0.5 & - & 0.5 \\
\hline
\end{tabular}

- Not applied.

a Assessed from the standard deviation from blank signal $(n=10)$ [33]. 
Table 4

Comparison of analytical figures of different flow methods for the determination of iron.

\begin{tabular}{|c|c|c|c|c|c|c|c|c|c|}
\hline System & Detection mode & $\begin{array}{l}\text { Range } \\
\left(\mu \mathrm{g} \mathrm{L}^{-1}\right)\end{array}$ & $\begin{array}{l}\text { Detection } \\
\text { limit } \\
\left(\mu \mathrm{g} \mathrm{L}^{-1}\right)\end{array}$ & $\begin{array}{l}\text { Determination } \\
\text { rate }\left(\mathrm{h}^{-1}\right)\end{array}$ & $\begin{array}{l}\text { Sample } \\
\text { volume } \\
(\mathrm{mL})\end{array}$ & $\begin{array}{l}\text { Reagent } \\
\text { consumption } \\
\text { (mmol/assay) }\end{array}$ & Matrix & Preconcentration & Reference \\
\hline$\overline{\text { FIA }}$ & UV-Vis. & $\begin{array}{l}\text { Up to } 4.2 \mathrm{Fe}(\mathrm{II})^{\mathrm{a}} \\
\text { Up to } 0.6 \mathrm{Fe}(\mathrm{II})^{\mathrm{b}} \\
\text { Up to } 11 \mathrm{Fe}(\mathrm{III})^{\mathrm{a}} \\
\text { Up to } 0.2 \mathrm{Fe}(\mathrm{III})^{\mathrm{c}}\end{array}$ & $\begin{array}{l}0.006 \mathrm{Fe}(\mathrm{II}) \\
0.017 \mathrm{Fe}(\mathrm{III})\end{array}$ & 3 & 40 & $0.001 \mathrm{FZ}$ & Aqueous (certified seawater) & $\mathrm{C} 18$ & {$[20]$} \\
\hline FIA & $\mathrm{CL}$ & $0.045-11$ & $\begin{array}{l}0.045 \mathrm{Fe}(\mathrm{II}) \\
0.020 \text { total } \mathrm{Fe}\end{array}$ & 9 & 5.6 & $\begin{array}{l}0.002 \text { BSF } \\
\mathrm{H}_{2} \mathrm{O}_{2} \text { n.g. }\end{array}$ & $\begin{array}{l}\text { Aqueous (river, rain and tap } \\
\text { waters and coastal seawater) }\end{array}$ & $\begin{array}{l}\text { Amberlite XAD-4 } \\
\text { with HEED groups }\end{array}$ & {$[25]$} \\
\hline Continuous flow & $\mathrm{CL}$ & $0.005-0.1$ & 0.003 & 5 & 18 & $\begin{array}{l}0.003 \text { luminol } \\
2.7 \mathrm{H}_{2} \mathrm{O}_{2}\end{array}$ & $\begin{array}{l}\text { Aqueous (seawaters and } \\
\text { seawaters samples) }\end{array}$ & MAF-8HQ & {$[26]$} \\
\hline FIA & UV-Vis. & Up to 0.5 & 0.001 & $\sim 12$ & n.g. & $\sim 0.001 \mathrm{DPD}$ & Aqueous (seawater) & Vinyl polymer-8HQ & {$[27]$} \\
\hline SIA & AAS & $\begin{array}{l}50-1200^{d} \\
20-400^{\mathrm{e}}\end{array}$ & $\begin{array}{l}12^{\mathrm{d}} \\
6^{\mathrm{e}}\end{array}$ & n.g. & $\begin{array}{l}9 \\
27\end{array}$ & n.n. & Aqueous (water samples) & Chelex 100 & [21] \\
\hline MSFIA & UV-Vis. & $0.05-8$ & 0.05 & 12 & 4 & $0.0006 \mathrm{FZ}$ & Aqueous (certified river water) & NTA Superflow & $\begin{array}{l}\text { Developed } \\
\text { method }\end{array}$ \\
\hline
\end{tabular}

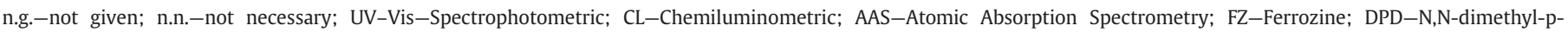

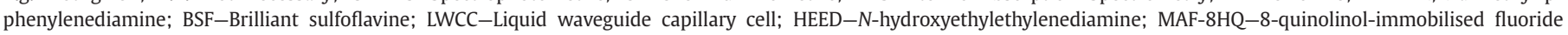
containing metal alkoxide glass.

a 2 min of loading time.

b 6 min of loading time.

c 10 min of loading time.

d $9 \mathrm{~mL}$ of sample.

e $27 \mathrm{~mL}$ of sample.

The result correspond to the average $(n=11)$ assays and the half width of $95 \%$ confidence interval. The certified sample was diluted fifty times in order to fit in the linear range. The result obtained for the sample shows a good accuracy for the developed method.

\section{Conclusion}

In this manuscript, a study on the comparison of the preconcentration resins of Chelex 100 with NTA Superflow resin and ammonium thiocyanate with ferrozine is demonstrated in the determination of iron.

From the developed work, NTA Superflow resin clearly present better operational stability moreover no additional conditioning solution is necessary. The developed method reached low detection limits for iron in waters with a good sampling rate. It should be emphasized that if sampling rate is not a crucial parameter, even lower detection limits can be reached by increasing the sample load.

In Table 4 there is a comparison of several features of different flow methods for the determination of iron. If compared with other existing spectrophotometric alternatives, the present work shows low reagent consumption and low effluent production.

The method developed is the first to combine a liquid waveguide capillary cell (LWCC) with a preconcentration resin in a MSFIA system. It can be also confirmed that the LWCC equipment provides a consistent and reliable option for increasing the sensitivity of spectrophotometric analytical procedures.

\section{Acknowledgements}

The authors thank Fundação para a Ciência e a Tecnologia (FCT) for financial support through Project PTDC/AMB/64441/2006. Ricardo Páscoa acknowledges financial support from FCT and FSE (III Quadro Comunitário) through the grant SFRH/BD/30621/2006.

\section{References}

[1] P.J. Worsfold, I.D. McKelvie, G. Hanrahan, Environmental applications: waters, sediments and soils, in: S. Kolev, I.D. McKelvie (Eds.), Advances in Flow Injection Analysis and Related Techniques, Elsevier, Amsterdam, 2008, pp. 685-760.

[2] K.H. Coale, K.S. Johnson, S.E. Fitzwater, R.M. Gordon, S. Tanner, F.P. Chavez, L. Ferioli, C.M. Sakamoto, P. Rogers, F. Millero, P. Steinberg, P. Nightingale, D. Cooper, W.P. Cochlan, M.R. Landry, J. Constantinou, G. Rollwagen, A. Trasvina, R. Kudela, A massive phytoplankton bloom induced by an ecosystem-scale iron fertilization experiments in the equatorial Pacific Ocean, Nature 383 (1996) 495-501.
[3] C.I. Measures, S. Vink, Seasonal variations in the distribution of Fe and $\mathrm{Al}$ in the surface waters of the Arabian Sea, Deep-Sea Res. Pt II 46 (1999) 1597-1622.

[4] A.J. Watson, D.C.E. Bakker, A.J. Ridgwell, P.W. Boyd, C.S. Law, Effect of iron supply on Southern Ocean $\mathrm{CO}_{2}$ uptake and implications for glacial atmospheric $\mathrm{CO}_{2}$, Nature 407 (2000) 730-733.

[5] E.P. Achterberg, T.W. Holland, A.R. Bowie, R.F.C. Mantoura, P.J. Worsfold, Review: determination of iron in seawater, Anal. Chim. Acta 442 (2001) 1-14.

[6] G. Hanrahan, S. Ussher, M. Gledhill, E.P. Achterberg, P.J. Worsfold, High temporal and spatial resolution environmental monitoring using flow injection with spectroscopic detection, Trends Anal. Chem. 21 (2002) 233-239.

[7] M.C. Lohan, A.M. Aguilar-Islas, R.P. Franks, Determination of iron and copper in seawater at $\mathrm{pH} 1.7$ with a new commercially available chelating resin, NTA Superflow, Anal. Chim. Acta 530 (2005) 121-129.

[8] I.P.A. Morais, M.R.S. Souto, A.O.S.S. Rangel, A double-line sequential injection system for the spectrophotometric determination of copper, iron, manganese and zinc in waters, J. AOAC Int. 88 (2005) 639-644.

[9] C. Pons, R. Forteza, V. Cerdà, Multi-pumping flow system for the determination, solidphase extraction and speciation analysis of iron, Anal. Chim. Acta 550 (2005) 33-39.

[10] D.M.C. Gomes, M.A. Segundo, J.L.F.C. Lima, A.O.S.S. Rangel, Spectrophotometric determination of iron and boron in soil extracts using multi-syringe flow injection system, Talanta 66 (2005) 703-711.

[11] V.A. Elrod, K.S. Johnson, K.H. Coale, Determination of subnanomolar levels of iron(II) and total dissolved iron in seawater by flow injection analysis with chemiluminescence detection, Anal. Chem. 63 (1991) 893-898.

[12] H. Matsumiya, N. Iki, S. Miyano, Sulfonylcalix[4]arenetetrasulfonate as pre-column chelating reagent for selective determination of aluminium(III), iron(II), and titanium(IV) by ion-pair reversed-phase high-performance liquid chromatography with spectrophotometric detection, Talanta 62 (2004) 337-342.

[13] R. Segura, M.I. Toral, V. Arancibia, Determination of iron in water samples by adsorptive stripping voltammetry with a bismuth film electrode in the presence of 1-(2-piridylazo)-2-naphthol, Talanta 75 (2008) 973-977.

[14] J.L. Chen, Z. Chang-Qing, Fluorescence enhancement assay for trace iron(II) using Pyr-tempo as a spin label fluorescence probe, Microchim. Acta 156 (2007) 307-313.

[15] X.P. Yan, M.J. Hendry, R. Herrich, Speciation of dissolved iron(III) and iron(II) in water by on-line coupling of flow injection separation and preconcentration with inductively coupled plasma mass spectrometry, Anal. Chem. 72 (2000) 1879-1884.

[16] R.C.C. Costa, A.N. Araújo, Determination of Fe(III) and total Fe in wines by sequential injection analysis and flame atomic absorption spectrometry, Anal. Chim. Acta 438 (2001) 227-233.

[17] M.A. Segundo, A.O.S.S. Rangel, Flow analysis: a critical view of its evolution and perspectives, J. Flow Injection Anal. 19 (2002) 3-8.

[18] V. Cerdà, R. Forteza, J.M. Estela, Potential of multisyringe flow-based multicommutated systems, Anal. Chim. Acta 600 (2007) 35-45.

[19] C. Pons, R. Forteza, A.O.S.S. Rangel, V. Cerdà, The application of multicommutated flow techniques to the determination of iron, Trends Anal. Chem. 25 (2006) 583-588.

[20] S. Blain, P. Treguer, Iron(II) and iron(III) determination in seawater at the nanomolar level with selective online preconcentration and spectrophotometric determination, Anal. Chim. Acta 308 (1995) 425-432.

[21] E. Rubí, M.S. Jiménez, F. Bauzá, R. de Mirabó, V.Cerdà Forteza, Preconcentration and atomic absorption determination of iron by sequential injection analysis, Talanta 44 (1997) 553-562.

[22] V. Cerdà, J.M. Estela, R. Forteza, A. Cladera, E. Becerra, P. Altimira, P. Sitjar, Flow techniques in water analysis, Talanta 50 (1999) 695-705.

[23] M. Miró, V. Cerdà, J.M. Estela, Multisyringe flow injection analysis: characterisation and applications, Trends Anal. Chem. 21 (2002) 199-210. 
[24] H.M. González-San Miguel, M. Fernández, J.M. Estela, V. Cerdà, Contribution of multicommuted flow analysis combined with monolithic columns to low-pressure, highperformance chromatography, Trends Anal. Chem. 28 (2009) 336-346.

[25] S. Hirata, H. Yoshihara, M. Aihara, Determination of iron(II) and total iron in environmental water samples by flow injection analysis with column preconcentration of chelating resin functionalized with $\mathrm{N}$-hydroxyethylethylenediamine ligands and chemiluminescence detection, Talanta 49 (1999) 1059-1067.

[26] H. Obata, H. Karatani, E. Nakayama, Automated determination of iron in seawater by chelating resin concentration and chemiluminescence detection, Anal. Chem. 65 (1993) 1524-1528.

[27] C.I. Measures, J. Yuan, J.A. Resing, Determination of iron in seawater by flow injection analysis using in-line preconcentration and spectrophotometric detection, Mar. Chem. 50 (1995) 3-12.

[28] J. de Jong, V. Schoemann, D. Lannuzel, J.L. Tison, N. Matielli, High-accuracy determination of iron in seawater by isotope dilution multiple collector inductively coupled plasma mass spectrometry (ID-MC-ICP-MS) using nitrilotriacetic acid chelating resin for pre-concentration and matrix separation, Anal. Chim. Acta 623 (2008) 126-139.
[29] K. Fuwa, W. Lei, K. Fujiwara, Colorimetry with a total reflection long capillary cell, Anal. Chem. 56 (1984) 1640-1644.

[30] Q. Li, K.J. Morris, P.K. Dasgupta, I.M. Raimundo, H. Temkin, Portable flow injection analyzer with liquid-core waveguide based fluorescence, luminescence, and long path length absorbance detector, Anal. Chim. Acta 479 (2003) 151-165.

[31] P. Vanloot, B. Coulomb, C. Brach-Papa, M. Sergent, J.-L. Boudenne, Multivariate optimization of solid-phase extraction applied to iron determination in finished waters, Chemosphere 69 (2007) 1351-1360.

[32] S.M.V. Fernandes, A.O.S.S. Rangel, J.L.F.C. Lima, Colorimetric determination of iron in beer by flow-injection analysis using the merging zones technique, J. Inst. Brew. 101 (1995) 281-284

[33] IUPAC-International Union of Pure and Applied Chemistry, Analytical Chemistry Division. Commission on spectrochemical and other optical procedures for analysis. Nomenclature, symbols, units and their usage in spectrochemical analysis. II. Data interpretation (Rules approved 1975, Pure Appl. Chem. 45 (1976) 99-103. 